\title{
افتتاحية العدد
}

يسر كلية الآداب - جامعة القاهرة أن ثقدم هذا العدد الجديد من الدجلة

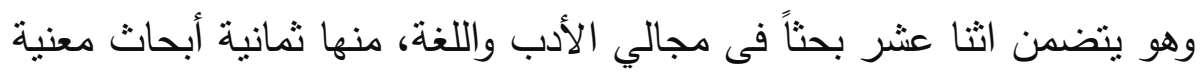

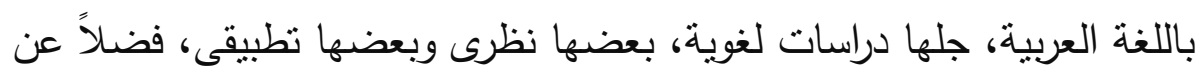
دراستين فى لغة الخطاب الروائ والرحلي، وهناك بحثان باللغة الإنجليزية،

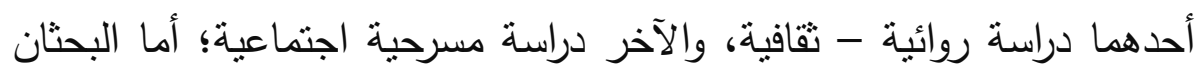

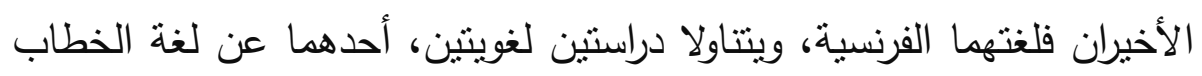

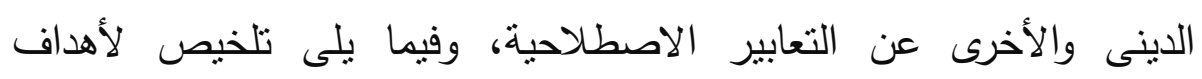

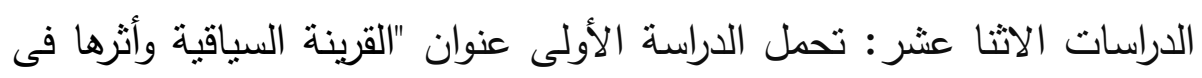

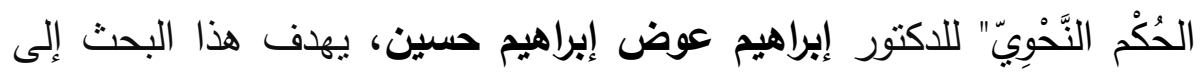

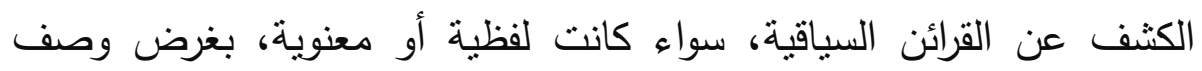
الجملة العربية وتحليلها، وتوضيح الحكم النحوى لعناصرها

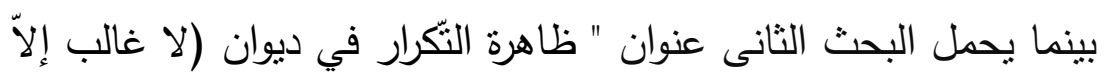

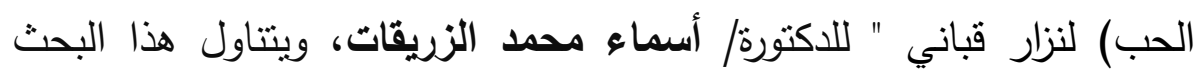

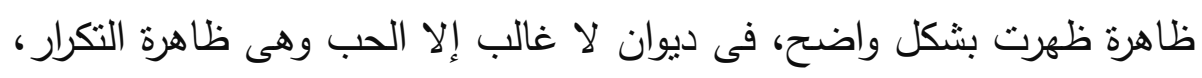

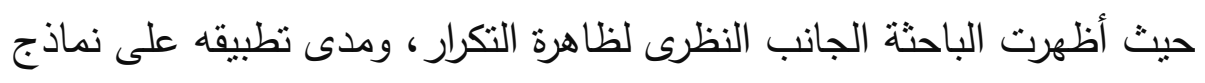

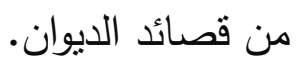

كما يحمل البحث الثالث عنوان " الخطاب الرحلي في كتاب الاعتبار

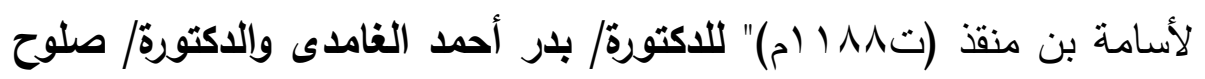

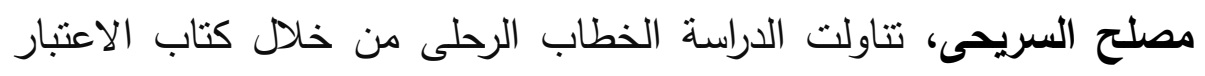

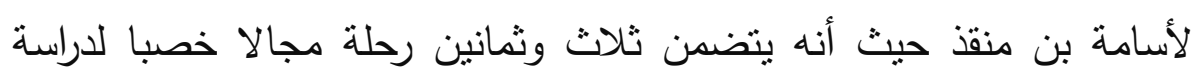

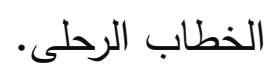

أما البحث الرابع فيحمل عنوان " البحث اللغوي في الجامعات السعودية:

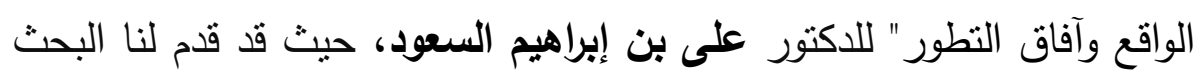

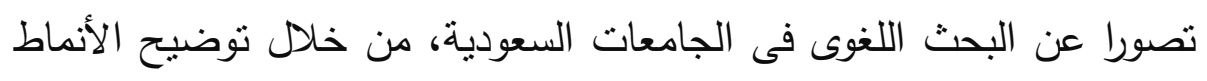




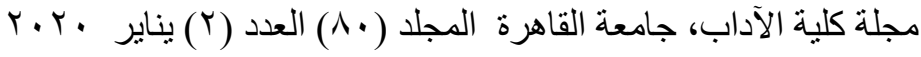

والمؤثرات فى البحث اللغوى، كما تتاول البحث المقررات الدراسية أو مدى تأثنيرها فى نشكيل هوية الموضورعات العملية.

كما يحمل البحث الخامس " أثز الإشعار في تفسير التحولات الصوتية

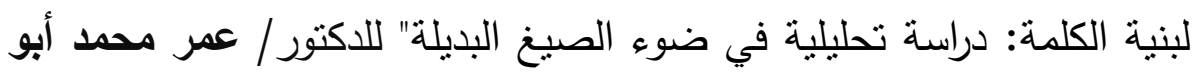

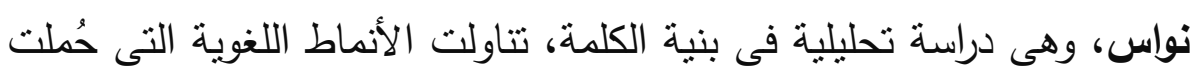
على الإشعار عند اللغوبين.

أما البحث السادس فيحمل عنوان" الدراسة الأسلوبية للشعر العربي القديم

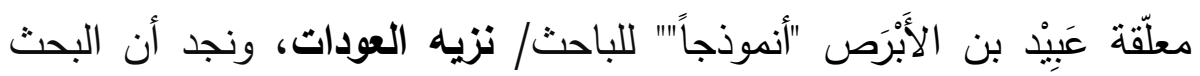

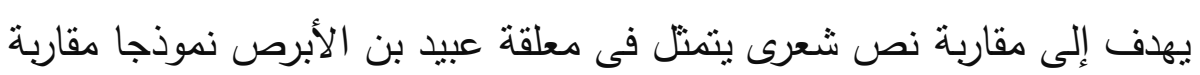

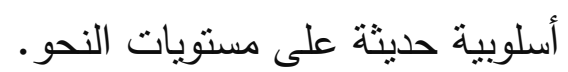

أما البحث السابع فيحمل عنوان " صورة الخطاب الروائي بين مرايا التاريخ

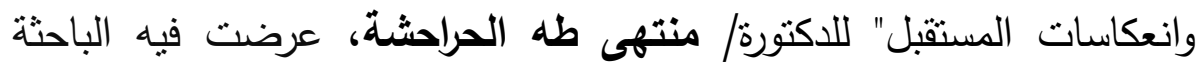
صورة الخطاب الروائى فى ضوء المنهج التاريخى لكى يظهر تجليات الخطاب الروائى والتاريخى، ويوضح الكتابة التاريخية والذات الروائية العربية. أما البحث الثامن فيحمل عنوان " ظاهرة الإعراب على المجاورة في تتاول النّحويّين والمفسّرين" للاكتور/ يحفظ عمرو انجية محمد عبد الله الشنقيطى، حيث تكمن أهمية البحث فى تتاوله لظاهرة إعرابية قديمة شائعة بين النحوبين

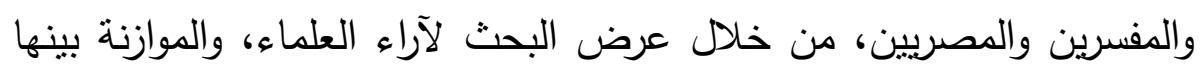
عبر العصور مع التحليل والمناقثة والتتبع والاستقراء. أما البحث التاسع باللغة الإنجليزية وعنوانه " الثتات والتهجين الثقافى الثى فى رواية الأرض المنخفضة للكاتبة جوميا لاهيرى" للاكتورة/ أمانى عبد الله الايسطى، يلقى البحث الضوء على الأزمة التاريخية التى انتجت هويات هندية الإنية جديدة، نتيجة لعملية الصراع التقافى والوصول إلى نهية هندى أمريكى. 
ويحمل البحث العاشر باللغة الانجليزية عنوان " حقوق الإنسان والازدواجية في تدابير شكسبير فى "تاجر البندقية" للدكتورة/ جيهان أنور محمود حيث يهذف البحث الى إظهار الإزدواجيه في المعايير من قبل أشخاص المسرحيه عند التعامل مع حقوق الاخرين وهي ازدواجيه قدمها شكسبير على أنها جزء من الطبيعة الإنسانية. والبحث الحادى عثر باللغة الفرنسية وعنوانه " مقاربة لغوية لتمبيز التعابير الاصطلاحية عن التراكيب المشابهة منل: المتلازمات اللفظية"

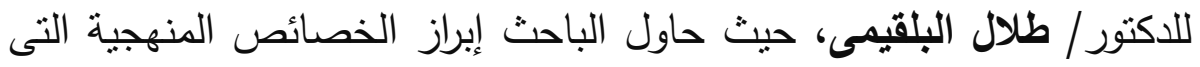

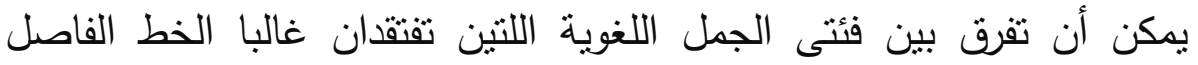

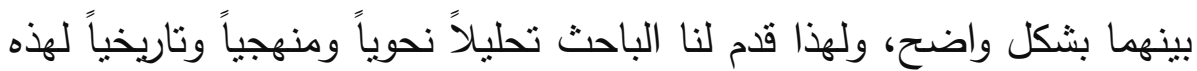
- التعابير

أما البحث الثانى عشر وعنوانه " العواطف والقضايا الجدلية" للاكتورة منى مصطقى لبيب، فيوضح مدى تمكن الخطيب من خلال تلاعبه بالعواطف المالائمة للحدث واختياره للحجج المستخدمة أثناء حديثه، للتأثير على المتلقين وكسبهم إلى صفه.

وفى النهاية نتوجه بخالص الثكر والتقدير لكل المشاركين بأبحاثهم الجادة والتى أتنىى أن يفيد منها الباحثّن.

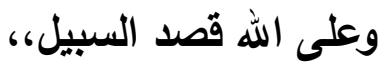

وكيل كلية الآداب لشئون الدراسات العليا والبحوث 